\title{
CABG in high risk patients: does the type of cardioplegia affect outcomes?
}

\author{
D Pena*, D Andrade, F Nunez, H Santos, H Orjuela, V Caicedo \\ From 23rd World Congress of the World Society of Cardio-Thoracic Surgeons \\ Split, Croatia. 12-15 September 2013
}

\section{Background}

Several cardioplegic solutions have been previously studied in patients undergoing CABG. However data on elderly high risk surgical patients is lacking. The main objective is to determined differences on mortality and clinical outcomes regarding the type of cardioplegic solution.

\section{Methods}

Consecutive high risk patients with a recient acute coronary syndrome(ACS) undergoing CABG on $\mathrm{CPB}$ inducing cardiac arrest were enrolled prospectively. A Comparison between those who received plegisol ${ }^{\circledR}(\mathrm{HCS})$ vs. Custodiol ${ }^{\circledR}(\mathrm{HTK})$ was performed. Statistical analysis of preoperative, operative and postoperative variables were done utilizing spss version 19.0.

\section{Results}

During 36 months, 721 patients underwent CABG. Only patients older that 70 years-old with an acute coronary syndrome were included. High risk was defined as Euroscore I greater than 7. Exclusion criterias were Chronic Renal Failure, off-pump surgery and additional procedures. $85(12 \%)$ patients were selected for analysis. Mean Age was 75(70-87). 56(65.9\%) were male and 29(34.1\%) were female. Mean Euroscore I was 10(8-20). Mean EF was $46 \%(+/-11)$. Left-main coronary obstruction was present in 13(15\%). Cardioplegic solution was administered randomly. HCS was administered to $40(47 \%)$ and HTK to $45(53 \%)$ patients. 30 days-Mortality occurred in 7(8.2\%), 4 in HCS and 3 in HTK (p:0.551). Mean CPB time was $84 \mathrm{~min}(42-110)$ and Cross-clamp time was $50 \mathrm{~min}$ (24-65) with no difference between groups. Number of grafts performed were 3(1-5) Perioperative infarction occurred in $11(12 \%)$ patients, $5(7.9 \%)$ in HTK and 6(5.9\%) in HCS (p:0.4), postoperative atrial fibrilation was present

\footnotetext{
* Correspondence: dpe000@hotmail.com
}

Cardiac Surgery, Fundacion Clinica Shaio, Bogota, Colombia in 15(17.5\%), 8 in HCS and 7 in HTK(p:0.4), Mean ICU time was 3days (1-5) for HTK and 5 for HCS (2-7). LOS was 4 for HTK and 6 days for HCS(p:0.2).

\section{Conclusion}

CABG outcomes in high risk patients with an acute coronary syndrome was not affected by the type of cardioplegia.

Published: 11 September 2013

doi:10.1186/1749-8090-8-S1-0195

Cite this article as: Pena et al.: CABG in high risk patients: does the type of cardioplegia affect outcomes? Journal of Cardiothoracic Surgery 2013 8(Suppl 1):0195.

Submit your next manuscript to BioMed Central and take full advantage of:

- Convenient online submission

- Thorough peer review

- No space constraints or color figure charges

- Immediate publication on acceptance

- Inclusion in PubMed, CAS, Scopus and Google Scholar

- Research which is freely available for redistribution 